\title{
Anti-diabetic and anti-oxidant potential of aged garlic extract (AGE) in streptozotocin- induced diabetic rats
}

\author{
Martha Thomson*, Khaled K. Al-Qattan, Divya JS and Muslim Ali
}

\begin{abstract}
Background: Although aged garlic extract (AGE) shares some active components with fresh garlic and in spite of its palatability and milder side effects, the anti-diabetic and related anti-oxidant properties of AGE have not been investigated extensively, and the reported findings are inconsistent.

This study investigated the anti-diabetic effects of 3 incremental doses of AGE in streptozotocin (STZ)-induced diabetic rats (fasting blood sugar $>20 \mathrm{mM}$ ).

Method: Diabetic rats were divided into a control diabetic group (CD) and AGE-treated diabetic group (AGE-D). The AGE-D was divided into 3 groups and accordingly treated with AGE i.p. at 100, 300 and $600 \mathrm{mg} / \mathrm{kg}$ daily for 8 weeks. A control normal group (CN) was also included for reference.

Results: Compared to the CN group, the CD group showed significant loss of body weight (over $50 \%$ ); and decreased serum insulin concentration (10 fold) and total anti-oxidant level and catalase activity (45-70\%) in serum, kidney and liver. Conversely, the CD rats had an elevated blood glucose (nearly 4 fold), serum cholesterol (nearly 2 fold) and triglycerides (>2 fold), erythrocyte glycated hemoglobin (GHb, 3 fold) and kidney and liver lipid peroxidation (MDA levels). Treatment with AGE positively reversed the diabetic changes in the targeted parameters to levels significantly lower than those measured in the CD group and the degrees of attenuation were almost dose dependent especially with the two higher doses.
\end{abstract}

Conclusion: AGE exhibits a dose-dependent ameliorative action on indicators of diabetes in STZ-induced diabetic rats.

Keywords: Aged garlic extract, Diabetes, Anti-diabetes

\section{Background}

Fresh garlic (Allium sativum L.), a widely used condiment and spice, is well known for its health-promoting properties as reported in numerous human and animal studies [1-14]. Garlic's health-promoting properties, which are of interest and fall within its antidiabetic potentials, are: hyperinsulinemia, hypoglycemia, hypocholesterolemia, hypotriglyceridemia and anti-glycation and anti-lipid peroxidation actions, in addition to promoting total anti-oxidant level and catalase activity. In spite of having these valuable ameliorative actions, fresh garlic consumption is, unfortunately, flawed by

\footnotetext{
* Correspondence: mmtkuniv@gmail.com

Department of Biological Sciences, Faculty of Science, Kuwait University, P.O. Box 5969, 13060 Safat, Kuwait
}

the manifestation of unpleasant side effects which sigbreath and body odor; sid garlic oil soluble sulfur-containing compounds. Another deterrent to the use of fresh garlic is its form and preparation, in addition to the inconsistency in the dose of ingested active ingredients.

Aged garlic extract (AGE), produced by storing sliced and macerated fresh garlic at room temperature for 20 months, is odorless and upon ingestion causes minimal gastrointestinal irritability and socially unacceptable properties. These preferable attributes of AGE seem to result from the aging process which reduces the oil-soluble 
odorous sulfur compounds and enhances the content of water-soluble compounds [15]. AGE is also available over the counter in a form suitable and ready for intake with a known dose concentration. What is also interesting about AGE is that it contains many of the bioactive compounds found in fresh garlic including the watersoluble allyl amino acid derivatives, stable lipid-soluble allyl sulfides, flavonoids and saponins, and most importantly and to a large extent, S-allylcysteine (SAC) and S-allylmercaptocysteine (SAMC) $[15,16]$.

In vitro and in vivo studies on AGE have demonstrated potent anti-thrombotic [17] and anti-oxidant [18] activities. In relation to the anti-thrombotic activity, AGE and its constituents have been shown to inhibit ADP-induced platelet aggregation in a dose dependent manner [19]. Inhibition of platelet aggregation by AGE has been reported to involve multiple mechanisms including changes in intra-platelet $\left[\mathrm{Ca}^{+2}\right]$, increase in intracellular cAMP and reduction in the interaction of fibrinogen with the CPIIb/IIIa receptor $[19,20]$. In relation to anti-oxidant properties, several studies have demonstrated that AGE and its components have potent anti-oxidant activity [14]. This activity is suggested to be the result of scavenging free radicals and enhancing the cellular anti-oxidant systems [18-21]. Furthermore, in animal models, AGE has been shown to lower oxidative stress (OS) by increasing endogenous anti-oxidant enzymes, such as catalase and glutathione peroxidase (GPx), [22] and lowering pro-oxidant enzymes such as xanthine oxidase and NADPH oxidase [23]. AGE can also reduce the formation of superoxide and lipid peroxidation and thus alleviate OS [24].

Diabetes mellitus (DM), an increasingly prevalent medical condition, is characterized by hyperglycemia, dyslipidemia and OS. Clinical and experimental studies have shown that diabetic hyperglycemia is a major source of OS, and that increased generation of free radicals plays a significant role in the pathogenesis and complications of DM [25-28]. Urate and vitamin C, major contributors to serum anti-oxidant activity, have shown to be significantly reduced in both insulin-dependent DM and non-insulindependent DM [29]. The basic mechanisms by which chronic hyperglycemia promote increased OS have been suggested to include glucose auto-oxidation, formation of advanced glycation end-products (AGEs) and increased activity of the sorbitol pathway [28-30].

During the last 20 years, many studies have investigated the anti-diabetic potential of fresh garlic. Our group and others have shown that raw garlic extract is active in reducing hyperglycemia and alleviating many diabetic indicators, such as dyslipidemia and OS in both animal models and humans [10, 13, 31-35]. However, few studies have examined the effects of AGE in diabetes and those reports have described variable effects of AGE on the classical indicators of DM. For example, Shiju and coworkers [36] reported that treating streptozotocin (STZ)-induced diabetic rats with $500 \mathrm{mg} / \mathrm{kg}$ of AGE for 12 weeks resulted in no change in blood glucose although hemoglobin glycation (GHb) was clearly reduced. In contrast, Balamash et al. [37] observed that treating type 2 DM patients with $3000 \mathrm{mg}$ of AGE daily for 3 months did not affect blood glucose, GHb or the serum lipid profile in these patients, although lipid peroxidation, an indicator of OS, was reduced.

Based on its acceptable palatability and milder side effects, content of potent bioactive components and conflicting reported effects in DM, the present study was carried out to assess the anti-diabetic potential of AGE by conducting an 8-week daily intraperitoneal (IP) three incremental dose-response study in STZ-induced diabetic rats. The doses investigated were selected based on a pilot study. In addition to examining the effect of AGE on the general indicators of diabetes, such as serum insulin and glucose, erythrocyte $\mathrm{GHb}$, food and water intake, urine output in addition to body weight changes, this study also looked at the indicators of OS and dyslipidemia to further delineate the scope of the anti-diabetic activity of this garlic preparation.

\section{Methods}

\section{Chemicals and kits}

AGE (Kyolic AGE) was purchased as a liquid suspension (Wakunaga, USA) containing $240 \mathrm{mg}$ AGE/ml. All analysis kits were purchased from the different sources as indicated in their respective usage in this section.

\section{Treatment of rats}

Healthy 3 month old male Sprague-Dawley rats (150-180 g BW) maintained on standard rodent diet and tap water ad libitum were used in the study. The rats were kept under standard ambient conditions $\left(23 \pm 2{ }^{\circ} \mathrm{C}, 12 \mathrm{~h}\right.$ light, 12 h darkness).

Diabetes was induced in 60 rats by a single IP injection of STZ, $60 \mathrm{mg} / \mathrm{kg}$ in $0.5 \mathrm{ml}$ of $0.01 \mathrm{M}$ sodium citrate buffer, pH 4.5. After 5 days, blood glucose was quantitated after overnight fasting in a drop of tail-blood under mild diethyl ether sedation using One-Touch Ultra-Easy Glucometer (LifeScan, UK).

Diabetic rats (blood sugar level $>20 \mathrm{mM}$ ) were divided into four groups (each, $n=12-16$ ): Control diabetic (CD) group injected IP daily with normal saline (NS); low-dose AGE-diabetic (AGE100-D) group injected IP daily with $100 \mathrm{mg}$ AGE / kg; medium dose AGE-diabetic (AGE300-D) group injected IP daily with $300 \mathrm{mg} \mathrm{AGE/}$ kg; high dose AGE-diabetic (AGE600-D) group injected IP daily with $600 \mathrm{mg}$ AGE $/ \mathrm{kg}$. A group of control normal rats $(\mathrm{CN})$ that received $\mathrm{NS}$ was included as a reference. 
The use of rats was in full compliance with the Guide for the Care and Use of Laboratory Animals [38] and all experimental protocols were approved by the Animal Care and Use Committee at Faculty of Science-Kuwait University.

Measurements, tissue preparation and biochemical assays The body weight of the rats in all groups was recorded before the start of the study and weekly during the experimental period. Twenty-four h water and food intake were measured weekly and $24 \mathrm{~h}$ urine output was measured in each treatment group at 8 weeks by housing the rats in metabolic cages.

After 8 weeks, the rats were sacrificed after overnight fast under Sodium Pentobarbitone $(10 \mathrm{mg} / \mathrm{kg}$, May \& Baker, England). The blood was collected by cardiac puncture into two separate tubes for serum and red blood cell (RBC) preparation. For serum, $3 \mathrm{ml}$ of blood was collected in a tube and allowed to clot for $30 \mathrm{~min}$ at room temperature. The tubes were centrifuged at $1000 \times \mathrm{g}$ for $15 \mathrm{~min}$ and the serum was separated, and stored as $0.5 \mathrm{ml}$ aliquots in Eppendorf tubes at $-80{ }^{\circ} \mathrm{C}$ for later analysis. For RBCs, $1 \mathrm{ml}$ of whole blood was collected in a separate glass tube containing $0.2 \mathrm{ml}$ of $3.8 \%$ sodium citrate as an anticoagulant and mixed well. The tubes were centrifuged at $1000 \times \mathrm{g}$ for $10 \mathrm{~min}$ and the plasma and buffy coat were carefully removed from the cells. RBCs was mixed well and analyzed for GHb on the same day.

Immediately after sacrifice, the liver and kidneys of each rat were collected separately. The capsule of each kidney was removed and the tissues were washed with buffer, blotted with filter paper and stored at $-40{ }^{\circ} \mathrm{C}$ for later analysis. One gram of kidney or liver tissue was diced and mixed with $3 \mathrm{ml}$ Tris- $\mathrm{HCl}(0.05 \mathrm{M}, \mathrm{pH}=7.6)$. The mixture was homogenized, allowed to stand on ice for a few minutes and then centrifuged for $15 \mathrm{~min}$ at 8000 $\times \mathrm{g}$ at $4{ }^{\circ} \mathrm{C}$. The supernatant was stored in small aliquots at $-40{ }^{\circ} \mathrm{C}$ for later analysis.

Glucose levels in whole blood were determined after overnight fasting at 2, 4, 8 weeks as described above. Total water-soluble antioxidants were determined by the method of Rice-Evans and coworkers as modified by Drobiova et al. [31] based on inhibition of the oxidation of 2, 2 -azinobis-(3-ethylbenzothiazoline-6-sulfonic acid) (ABTS). Serum insulin was determined by ELISA using kits supplied by SPIbio (France). Total serum cholesterol and triglycerides were determined spectrophotometrically using test kits from Randox (USA). Serum GHb was determined by an affinity chromatography method using analysis kits from Helena Laboratories (USA). Serum catalase was determined spectrophotometrycally by the method of Aebi [39]. Serum superoxide dismutase (SOD) was determined spectophotometrically by a coupled assay using a kit supplied by Cayman Chemical
Company (USA). Lipid peroxidation was assessed by reaction of malondialdehyde (MDA) with thiobarbituric acid according to the method of Ohkawa et al. [40]. Total serum and tissue protein levels were determined by the Coomassie Blue dye binding method of Bradford [41].

\section{Statistical analysis}

Data are expressed as mean +/- SEM. Statistical analysis was carried out using SPSS V. 21 (IBM). Readings within each group were compared using the independent sample test, whereas the readings of the different groups were compared using One-Way ANOVA: Post hoc multiple comparisons test. In Post Hoc, equal variances were assumed by Fisher's Least Significant Difference, (LSD) with $P<0.05$ being significant.

\section{Results}

\section{Effect of AGE on physical measurements}

During the 8 weeks of the study, the $\mathrm{CN}$ rats more than doubled in weight (Fig. 1) while the CD rats lost weight and were over $50 \%$ lighter at 8 weeks compared to the start of the experiment. In comparison, AGE-D rats recovered in terms of body weight after an initial loss following STZ injection in a dose-dependent manner with a significant increase in weight in AGE300-D and AGE600-D treatment groups compared to CD rats.

The CD rats greatly increased water $(235 \pm 3 \mathrm{ml} / 24 \mathrm{~h})$ and food $(46 \pm 2 \mathrm{~g} / 24 \mathrm{~h}$ ) intake during the experiment compared to $\mathrm{CN}$ rats $(40 \pm 1 \mathrm{ml} / 24 \mathrm{~h}, 30 \pm 1 \mathrm{gm} / 24$, respectively) (Table 1 ). AGE treatment of diabetic rats at a dose of $600 \mathrm{mg} / \mathrm{kg}$ led to a significantly less food $(34 \pm 3 \mathrm{gm} / 24 \mathrm{~h})$ and water $(185 \pm 2 \mathrm{ml} / 24 \mathrm{~h})$ intake in comparison to $C D$ rats. The two lower doses of AGE did not have an effect on either food or water intake.

In comparison, urine output (Table 1 ) in $\mathrm{CD}$ rats was over 9 times $(95 \pm 2 \mathrm{ml} / 24 \mathrm{hrs})$ the output in $\mathrm{CN}$ animals $(10 \pm 1 \mathrm{ml} / 24 \mathrm{hrs})$. The diabetic animals treated with AGE at 300 and $600 \mathrm{mg} / \mathrm{kg}$ had significantly reduced urine output (89 \pm 3 and $87 \pm 2 \mathrm{ml} / 24$ hrs, respectively). In comparison, the lowest dose of AGE $(100 \mathrm{mg} / \mathrm{kg})$ did not have an effect on urine output (92 $\pm 1 \mathrm{ml} / 24 \mathrm{hrs})$ compared to CD rats.

\section{Effect of AGE on blood glucose, glycated hemoglobin and serum insulin}

As shown in Fig. 2, blood glucose levels in untreated CD rats continued to increase throughout the experimental period, while glucose levels in diabetic rats treated with 300 or $600 \mathrm{mg} / \mathrm{kg}$ of AGE decreased significantly. In contrast, blood glucose levels in diabetic rats treated with 100 $\mathrm{mg} / \mathrm{g}$ dose of AGE were not significantly different from the readings of the $C D$ rats. 


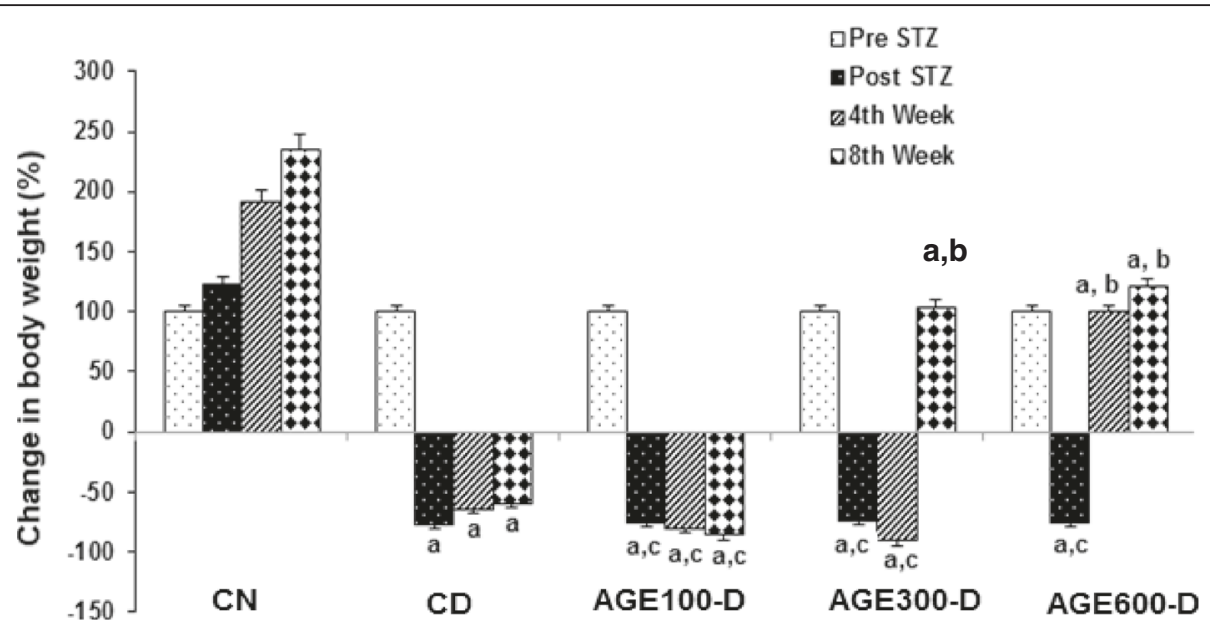

Fig. 1 Dose response of aged garlic extract (AGE) on body weight in diabetic rats. AGE at doses of $100 \mathrm{mg} / \mathrm{kg}, 300 \mathrm{mg} / \mathrm{kg}$ and $600 \mathrm{mg} / \mathrm{kg}$ were administered IP to diabetic rats for 8 weeks abbreviated as AGE100-D, AGE300-D and AGE600-D, respectively. Diabetic control rats (CD) and normal control rats (CN) were administered normal saline. The animals were weighed before STZ injection (Pre STZ), 1 week after STZ injection (Post STZ) and at weeks 4 and 8 of the experiment. Weights are plotted as percentiles with the starting weights all standardized to $100 \%$. $a=$ significantly decreased compared to normal saline rats; $b=$ significantly increased compared to diabetic control; $c=$ not significantly different from diabetic control

As shown in Fig. 3, induction of diabetes with STZ resulted in approximately 11 -fold reduction in serum insulin level $(0.01 \pm 0.00 \mathrm{ng} / \mathrm{ml})$ compared to $\mathrm{NC}$ rats $(1.15 \pm 0.02 \mathrm{ng} / \mathrm{ml})$. AGE treatment of diabetic rats with doses of 100,300 or $600 \mathrm{mg} / \mathrm{kg}$ resulted in a higher serum insulin with increases of $9 \%(0.09 \pm 0.01 \mathrm{ng} / \mathrm{ml})$, $34 \%(0.40 \pm 0.03 \mathrm{ng} / \mathrm{ml})$ and $64 \%(0.75 \pm 0.05 \mathrm{ng} / \mathrm{ml})$, respectively. In contrast and in agreement with serum glucose levels, $\mathrm{GHb}$ was significantly higher in $\mathrm{CD}$ rats $(24.9 \pm 1.7 \%)$ compared to $\mathrm{CN}$ rats $(7.8 \pm 0.4 \%)$. GHb levels were significantly decreased by the 300 and 600 $\mathrm{mg} / \mathrm{kg}$ doses of AGE $(19.7 \pm 0.8$ and $16.0 \pm 1.2$, respectively), while the $100 \mathrm{mg} / \mathrm{kg}$ dose of AGE did not have an effect on this parameter.

\section{Effect of AGE on serum triglyceride and total cholesterol} Figure 4 shows that serum total cholesterol $(3.0 \pm 0.1$ $\mathrm{mM})$ and triglycerides $(1.25 \pm 0.10 \mathrm{mM})$ were significantly increased in $\mathrm{CD}$ rats compared to $\mathrm{CN}$ rats $(1.6 \pm$

Table 1 Dose response of aged garlic extract (AGE) on $24 \mathrm{~h}$ urine output, food intake and water intake in diabetic rats

\begin{tabular}{lcccc}
\hline Group & $\mathrm{n}$ & $\begin{array}{l}\text { Urine output } \\
(\mathrm{ml} / 24 \mathrm{~h})\end{array}$ & $\begin{array}{l}\text { Food intake } \\
(\mathrm{gm} / 24 \mathrm{~h})\end{array}$ & $\begin{array}{c}\text { Water intake } \\
(\mathrm{ml} / 24 \mathrm{~h})\end{array}$ \\
\hline CN & 12 & $10 \pm 1$ & $30 \pm 1$ & $40 \pm 1$ \\
CD & 12 & $95 \pm 2^{\mathrm{a}}$ & $46 \pm 2^{\mathrm{a}}$ & $235 \pm 3^{\mathrm{a}}$ \\
AGE 600-D & 16 & $87 \pm 2^{\mathrm{a}, \mathrm{b}}$ & $34 \pm 3^{\mathrm{a}, \mathrm{b}}$ & $185 \pm 2^{\mathrm{a}, \mathrm{b}}$ \\
AGE 300-D & 15 & $89 \pm 3^{\mathrm{a}, \mathrm{b}}$ & $41 \pm 2^{\mathrm{a}, \mathrm{c}}$ & $225 \pm 1^{\mathrm{a}, \mathrm{c}}$ \\
AGE 100-D & 15 & $92 \pm 1^{\mathrm{a}, \mathrm{c}}$ & $41 \pm 3^{\mathrm{a}, \mathrm{c}}$ & $232 \pm 1^{\mathrm{a}, \mathrm{c}}$ \\
\hline
\end{tabular}

$\mathrm{a}=$ significantly decreased compared to normal saline rats; $\mathrm{b}=$ significantly increased compared todiabetic control; $c=$ not significantly different from diabetic control
0.04 and $0.57 \pm 0.03 \mathrm{mM}$, respectively). The 2 higher doses of AGE significantly lessened the increase in the level of cholesterol $(1.7 \pm 0.1$ and $1.8 \pm 0.1 \mathrm{mM}$, respectively) and triglycerides $(0.77 \pm 0.07$ and $0.95 \pm$ $0.09 \mathrm{mM}$, respectively) compared to $\mathrm{CD}$, while treatment of diabetic rats with the $100 \mathrm{mg} / \mathrm{kg}$ dose was not effective in attenuating the increases in either cholesterol $(2.7 \pm 0.08 \mathrm{mM})$ or triglycerides $(1.12 \pm 0.03 \mathrm{mM})$ in serum.

Effect of AGE on oxidative stress in serum, kidney and liver Figure 5 illustrates that serum total anti-oxidants, catalase and superoxide dismutase activities (SOD) were significantly decreased in CD rats $(0.0063 \pm 0.0005 \mathrm{mM}$, $0.0007 \pm 2 \times 10^{-6} \mathrm{U} / \mathrm{mg}$ protein, $4.89 \pm 0.34 \mathrm{U} / \mathrm{ml}$, respectively) compared to $\mathrm{CN}$ rats $(0.02 \pm 0.01 \mathrm{mM}$, $0.0023 \pm 4 \times 10^{-5} \mathrm{U} / \mathrm{mg}$ protein, $7.95 \pm 0.62 \mathrm{U} / \mathrm{ml}$, respectively). Total serum antioxidants and catalase activity were significantly increased by treatment of diabetic rats with $300\left(0.14 \pm 0.009 \mathrm{mM}, 0.0013 \pm 3 \times 10^{-5}\right.$ $\mathrm{U} / \mathrm{mg}$ protein, $4.97 \pm 0.33 \mathrm{U} / \mathrm{ml}$ ) and $600 \mathrm{mg} / \mathrm{kg}$ of $\mathrm{AGE}$ $\left(0.017 \pm 0.01 \mathrm{mM}, 0.002 \pm 4 \times 10^{-5} \mathrm{U} / \mathrm{mg}\right.$ protein, respectively). Serum SOD activity was only significantly increased in diabetic rats treated with $600 \mathrm{mg} \mathrm{AGE} / \mathrm{kg}$. The lowest AGE dose $(100 \mathrm{mg} / \mathrm{kg})$ had no effect on serum antioxidant parameters.

In parallel with serum anti-oxidants and catalase, total kidney and liver anti-oxidants and catalase activity were significantly lower in CD rats (Figs. 6 and 7). Treatment with AGE at doses of 300 and $600 \mathrm{mg} / \mathrm{kg}$ resulted in significantly higher kidney and liver anti-oxidants and catalase activity. In contrast, kidney and liver MDA 


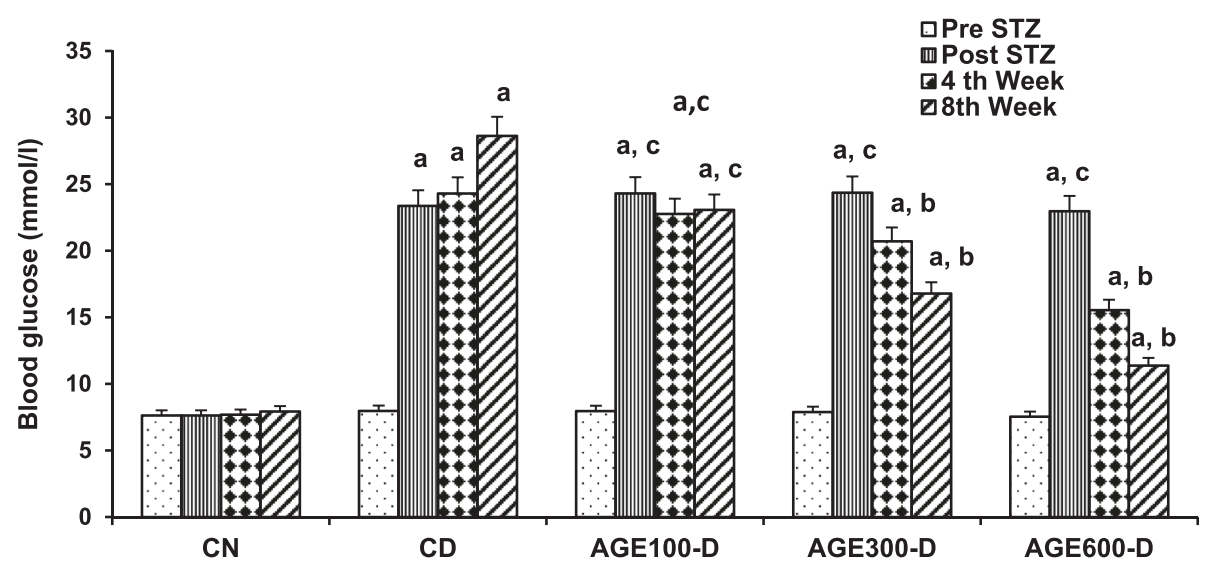

Fig. 2 Dose response of aged garlic extract (AGE) on blood glucose levels in diabetic rats. AGE at doses of $100 \mathrm{mg} / \mathrm{kg}, 300 \mathrm{mg} / \mathrm{kg}$ and $600 \mathrm{mg} /$ $\mathrm{kg}$ were administered IP to diabetic rats for 8 weeks abbreviated as AGE100-D, AGE300-D and AGE600-D, respectively. Diabetic control rats (CD) and normal control rats (CN) were administered normal saline. Blood glucose levels were measured before STZ injection (Pre STZ), 1 week after STZ injection (Post STZ) and at weeks 4 and 8 of the experiment. $a=$ significantly increased compared to normal saline rats; $b=$ significantly decreased compared to diabetic control; $c=$ not significantly different from diabetic control

levels were significantly higher in $\mathrm{CD}$ rats compared to $\mathrm{CN}$ rats. AGE-treated rats with the 300 and $600 \mathrm{mg} / \mathrm{kg}$ doses exhibited significantly decreased kidney and liver MDA levels. Note that the lowest dose of AGE (100 mg/ $\mathrm{kg}$ ) significantly increased kidney catalase activity and decreased kidney MDA levels, but had no effect on these anti-oxidant markers in liver tissues.

\section{Discussion}

During the last two decades, considerable research has been devoted to studying the effects of natural herbs and spices as alternative forms of treatment for chronic diseases such as DM. Extensive research has established that fresh garlic extract and some garlic constituents have anti-diabetic and anti-oxidant properties. However,
AGE, an over the counter available stable garlic preparation with known composition, in addition to acceptable ingestion and side effects attributes, has received little attention as an anti-diabetic agent. The goal of the present study was to assess the anti-diabetic and related anti-oxidant potential of AGE, which is either lacking in certain aspects or controversially reported in with respect to other aspects in the literature. Toward that objective and to define the most active dose or range of doses, a three incremental-dose-response study of AGE was investigated in STZ-induced diabetic rats.

Prolonged hyperglycemia in both human conditions and animal models has been shown to result in the physical symptoms of diabetes including weight loss, polyphagia, polydipsia and polyuria [42, 43]. As expected, in the

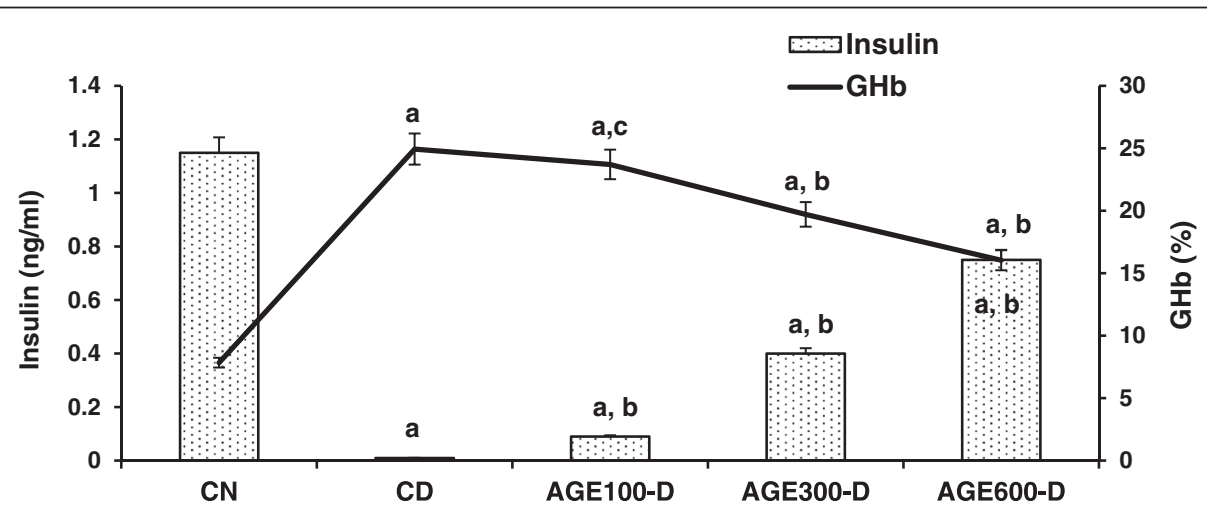

Fig. 3 Dose response of aged garlic extract (AGE) on serum insulin and RBC GHb in diabetic rats. AGE at doses of $100 \mathrm{mg} / \mathrm{kg}, 300 \mathrm{mg} / \mathrm{kg}$ and $600 \mathrm{mg} / \mathrm{kg}$ were administered IP to diabetic rats for 8 weeks abbreviated as AGE100-D, AGE300-D and AGE600-D, respectively. Diabetic control rats $(C D)$ and normal control rats (CN) were administered normal saline. Serum insulin levels and glycated hemoglobin (GHb) in red blood cells were measured at the conclusion of the treatment period ( 8 weeks). $a=$ significantly different compared to normal saline rats; $b=$ significantly different compared to diabetic control; $c=$ not significantly different from diabetic control 


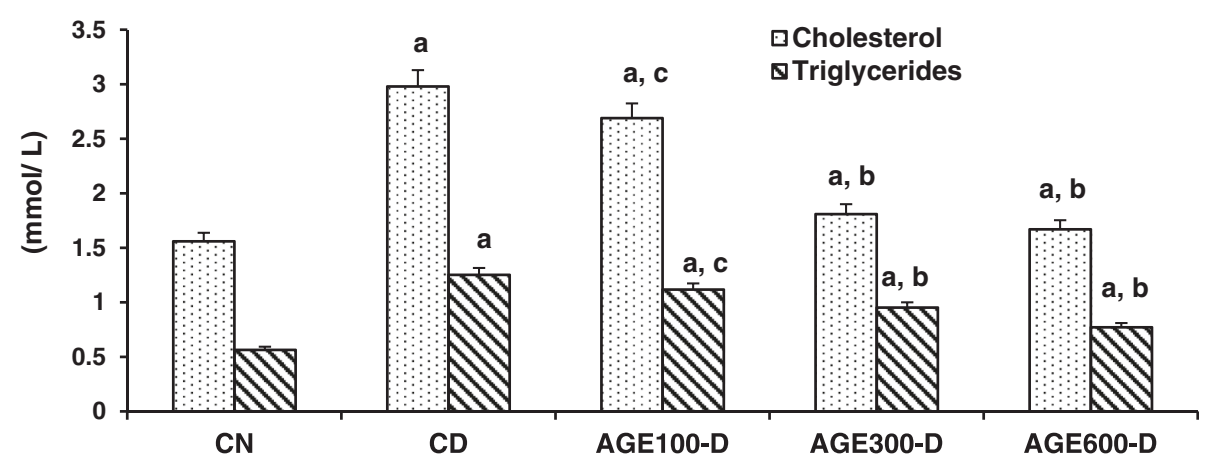

Fig. 4 Dose response of aged garlic extract (AGE) on serum total cholesterol and triglycerides in diabetic rats. AGE at doses of $100 \mathrm{mg} / \mathrm{kg}$, 300 $\mathrm{mg} / \mathrm{kg}$ and $600 \mathrm{mg} / \mathrm{kg}$ were administered IP to diabetic rats for 8 weeks abbreviated as AGE100-D, AGE300-D and AGE600-D, respectively. Diabetic control rats (CD) and normal control rats (CN) were administered normal saline. Serum total cholesterol and triglyceride levels were measured at the conclusion of the treatment period ( 8 weeks). $a=$ significantly increased compared to normal saline rats; $b=$ significantly decreased compared to diabetic control; $c=$ not significantly different from diabetic control

present study, the STZ-induced CD rats rapidly developed and maintained these physical symptoms and exhibited over $50 \%$ weight loss during the 8 week experiment. The lowest dose of AGE $(100 \mathrm{mg} / \mathrm{kg})$ did not have a marked effect on these parameters, while the AGE-D rats treated with the 300 or $600 \mathrm{mg} / \mathrm{kg}$ doses stabilized their weight after an initial weight loss, in addition to an improved polydipsia, polyphagia and polyuria in diabetic rats treated with $600 \mathrm{mg}$ AGE/kg. Lessening of polyuria in response to AGE is consistent with the results of Shiju and coworkers [36] who reported amelioration of polyuria in a $500 \mathrm{mg} / \mathrm{kg}$ oral AGE treated STZ-induced diabetic rats.

In the present study, STZ-injected rats developed a rapid hyperglycemia and hypoinsulinemia as shown previously by our group and others [44-46]. Treating diabetic rats with either 300 or $600 \mathrm{mg} / \mathrm{kg}$ dose of AGE significantly decreased blood glucose and markedly increased serum insulin. These results are in contrast with those of
Shiju et al. [36] who did not observe any hypoglycemic effect of AGE. However, with respect to the anti-glycation effects, both the current study and that of Shiju et al. [36] showed that AGE treatment leads to a decrease in GHb. Thus, these results suggest that AGE may prevent formation of Amadori products which can lead to protein oxidation. This conclusion is supported by reports that AGE has potent anti-glycation potential, which may be one of the mechanisms by which AGE exerts its protective action in DM $[47,48]$.

Dyslipidemia, a major symptom and risk factor for the development of cardiovascular diseases in DM $[49,50]$ is characterized by high serum levels of both triglycerides and cholesterol. Previous studies in both humans and animals have reported that AGE has a lipid-lowering property [51]. Similarly, in the present study and as reported by Shiju et al. [36], treatment with all doses of AGE led to a significant attenuation of the elevation of

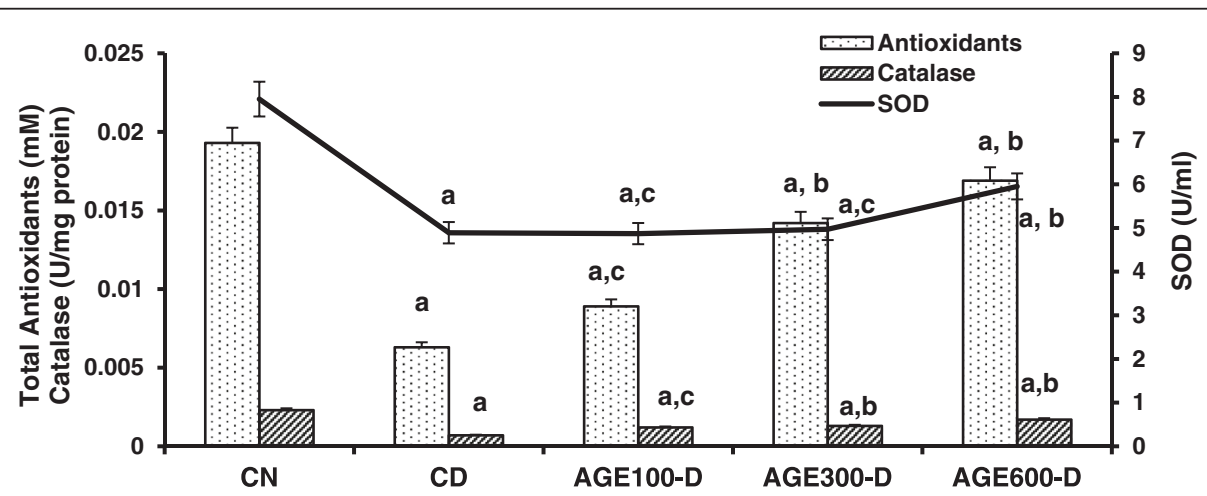

Fig. 5 Dose response of aged garlic extract (AGE) on serum total antioxidants, catalase and SOD in diabetic rats. AGE at doses of $100 \mathrm{mg} / \mathrm{kg}, 300$ $\mathrm{mg} / \mathrm{kg}$ and $600 \mathrm{mg} / \mathrm{kg}$ were administered IP to diabetic rats for 8 weeks abbreviated as AGE100-D, AGE300-D and AGE600-D, respectively. Diabetic control rats (CD) and normal control rats (CN) were administered normal saline. Serum total antioxidants (mM), catalase activity (U/mg protein) and SOD activity $(\mathrm{U} / \mathrm{ml})$ were determined at the conclusion of the treatment period (8 weeks). $a=$ significantly decreased compared to normal saline rats; $b=$ significantly increased compared to diabetic control; $c=$ not significantly different from diabetic control 


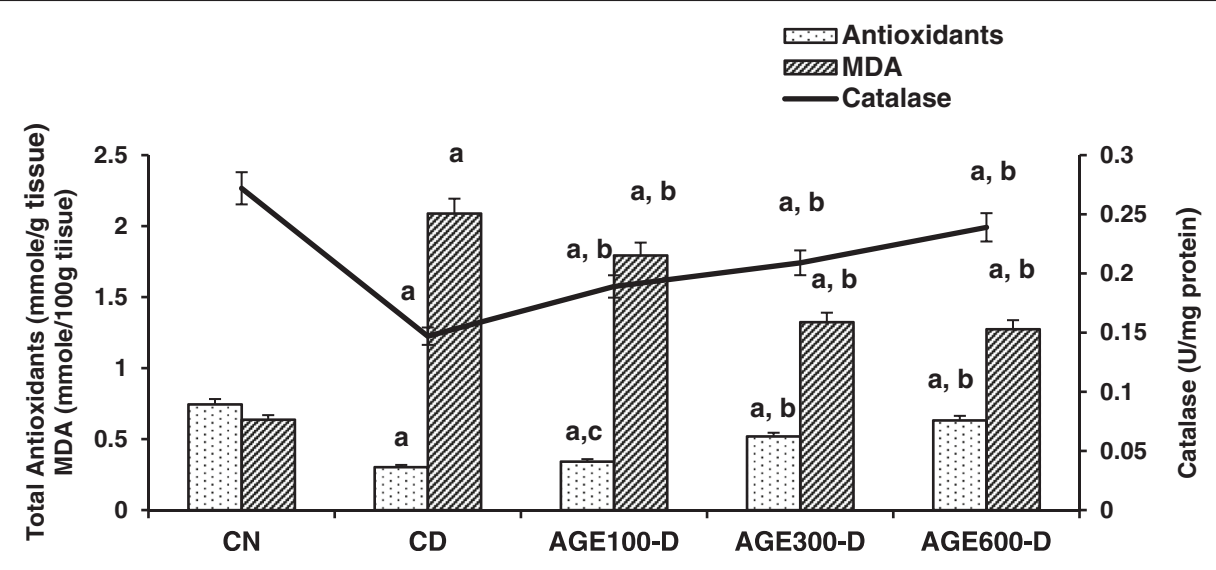

Fig. 6 Dose response of aged garlic extract (AGE) on kidney total antioxidants, catalase and MDA in diabetic rats. AGE at doses of $100 \mathrm{mg} / \mathrm{kg}, 300$ $\mathrm{mg} / \mathrm{kg}$ and $600 \mathrm{mg} / \mathrm{kg}$ were administered IP to diabetic rats for 8 weeks abbreviated as AGE100-D, AGE300-D and AGE600-D, respectively. Diabetic control rats (CD) and normal control rats (CN) were administered normal saline. Total antioxidants (mmole/g tissue), catalase activity (U/mg protein) and MDA levels (mmole/100 g tissue) were determined in kidney tissue at the conclusion of the treatment period ( 8 weeks). $a=$ significantly diferent compared to normal saline rats; $b=$ significantly different compared to diabetic control; $c=$ not significantly different from diabetic control

both serum triglycerides and total cholesterol observed in the $\mathrm{CD}$ rats. Interestingly, treatment of type 2 diabetic patients with $3000 \mathrm{mg}$ of AGE daily had no effect on serum cholesterol but did slightly, although not significantly, lower serum triglycerides after 3 months of treatment [37]. These observations in the type-2 diabetes suggest that part of the AGE ameliorative mechanism of action on body lipids may be mediated at the cellular level.

Oxidative stress has been implicated as a key contributor to many diabetic complications, including nephropathy [26]. Thus, alleviation of OS is expected to reverse or at least lessen many of the negative impacts of DM. A number of studies have investigated the antioxidant potential of AGE and have suggested that AGE attenuates OS by increasing endogenous anti-oxidant enzymes, such as catalase and glutathione peroxidase [22]. In addition, in vitro and in vivo studies have indicated that AGE can reduce both the formation of superoxide and lipid peroxidation, and thus alleviate OS [24]. In spite of the established connection between OS and DM, the anti-oxidant potential of AGE has not previously been studied in DM. In the current study, indicators of OS were assessed in serum as well as kidney and liver tissues of STZ-induced diabetic rats. As we have previously reported, anti-oxidants were decreased and OS was increased in serum, liver and kidneys of this experimental model of $C D$ rats $[31,44]$. Treatment with either 300 or $600 \mathrm{mg} / \mathrm{kg}$ of AGE significantly increased the anti-oxidant defense systems as

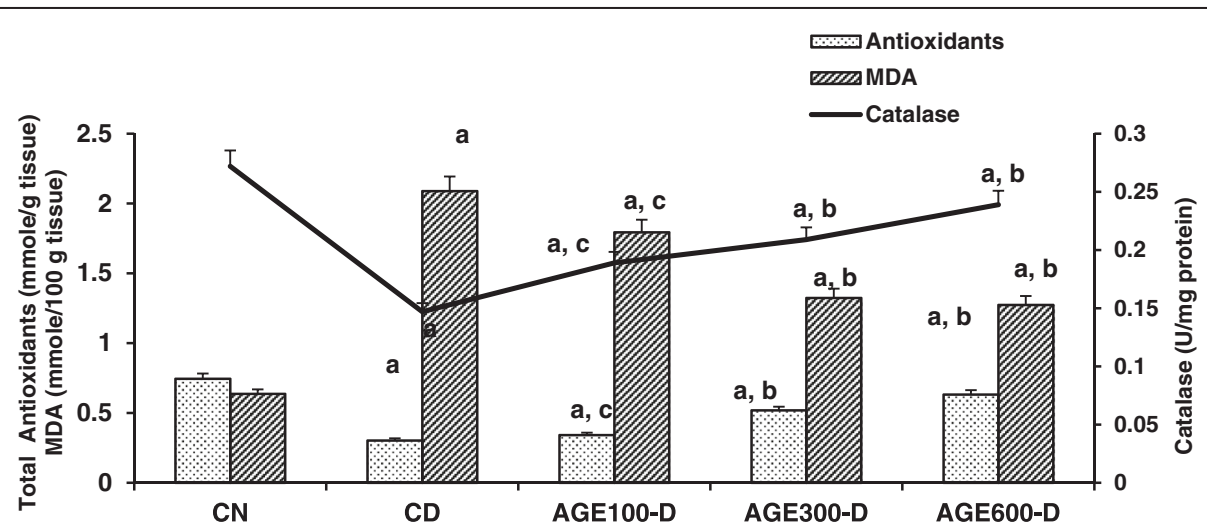

Fig. 7 Dose response of aged garlic extract (AGE) on liver total antioxidants, catalase and MDA in diabetic rats. AGE at doses of $100 \mathrm{mg} / \mathrm{kg}$, $300 \mathrm{mg} / \mathrm{kg}$ and $600 \mathrm{mg} / \mathrm{kg}$ were administered IP to diabetic rats for 8 weeks abbreviated as AGE100-D, AGE300-D and AGE600-D, respectively. Diabetic control rats (CD) and normal control rats (CN) were administered normal saline. Total antioxidants (mmole/g tissue), catalase activity (U/mg protein) and MDA levels (mmole/100 $\mathrm{g}$ tissue) were determined in liver tissue at the conclusion of the treatment period ( 8 weeks). $a=$ significantly different compared to normal saline rats; $b=$ significantly different compared to diabetic control; $c=$ not significantly different from diabetic control 
indicated by increased levels of total anti-oxidants and anti-oxidant enzymes and lowered lipid peroxidation in liver and kidney tissues. In agreement, Balamash et al. [37] also reported decreased lipid peroxidation in AGEtreated diabetic patients.

In an attempt to specify the active components of AGE, Saravanan et al. [50] investigated the anti-diabetic properties of SAC, the major garlic-derived component found in AGE, in STZ-induced diabetic rats. Those investigators reported that SAC at 100 and $150 \mathrm{mg} / \mathrm{kg}$ decreased blood glucose and GHb and increased serum insulin. Thus, Saravanan and coworkers [52] suggested that SAC may be responsible for the anti-diabetic effect of AGE. The increase in insulin concentration induced by AGE may be the mechanism by which SAC brings about its actions. This mechanism of action may not be different from that suggested for fresh garlic. Therefore, we propose that the anti-diabetic actions of AGE are due to amendment of the insulin-glucose biochemical pathway. This point of view is based on the fact that many diabetic symptoms are consequences of cellular abnormalities resulting from hypoinsulinemia-hyperglycemia. The different doses of AGE tested gave some indication as to the potency of this natural product preparation, in addition to suggesting a suitable and tolerable dose that can be taken as a supplement by diabetics. Although AGE has many of the same active components as fresh garlic, the process of aging may have led to attenuation in the potency of these active components. For that reason, a larger dose of AGE $(600 \mathrm{mg} / \mathrm{kg})$ may be required to induce almost similar actions to those induced by a slightly lower dose of fresh garlic $(500 \mathrm{mg} / \mathrm{kg})$.

\section{Conclusion}

In conclusion, the observed attenuating effects of AGE on the diabetic indicators in STZ-induced diabetic rats suggest that this ready-to-use, fixed concentration, stable preparation has the potential to be used as a palatable anti-diabetic agent. Further biochemical and pharmacological investigations into the insulin-glucose pathway are necessary to further elucidate the anti-diabetic and connected anti-oxidant mechanism of action of AGE to support its use as a possible supplementary treatment in DM.

\section{Abbreviations}

AGE: Aged garlic extract; AGE100-D: Low dose AGE-diabetic; AGE300D: Medium dose AGE-diabetic; AGE600-D: High dose AGE-diabetic; CD: Control diabetic; CN: Control normal; DM: Diabetes mellitus; GHb: Glycated hemoglobin; GPx: Glutathione peroxidase; NS: Normal saline; OS: Oxidative stress; SAC: S-allylcysteine; SAMC: S-allylmercaptocysteine; SOD: Superoxide dismutase; STZ: Streptozotocin.

\section{Authors' contributions}

MT and MA designed the study; MT, DJS and KKA performed experiments; MT, MA and DJS analyzed and interpreted the data; MT, MA and KKA drafted the manuscript; MT, KKA, DJS and MA approved the version of the manuscript. All authors read and approved the final manuscript.

\section{Author details}

All authors are from the Department of Biological Sciences, Faculty of Science, Kuwait University, P.O. Box 5969, 13060-Safat, Kuwait.

\section{Acknowledgements}

The present study was supported Kuwait University (KU) grant \# SL 02/13.

Received: 9 May 2015 Accepted: 8 January 2016

Published online: 19 January 2016

\section{References}

1. Ali M, Thomson M, Alnageeb MA, Al-Hassan JM, Khater SH, Gomes SA. Antithrombotic activity of garlic: its inhibition of the synthesis of thromboxane- $\mathrm{TX}_{2}$ during infusion of arachidonic acid and collagen in rabbits. Prostaglan Leukot Essent Fatty Acids. 1990;41:5-9.

2. Ali M, Al-Qattan K, Al-Enezi F, Khanafer R, Mustafa T. Effect of allicin from garlic powder on serum lipids and blood pressure in rats fed with a high cholesterol diet. Prostaglan Leukot Essent Fatty Acids. 2000;62:253-9.

3. Ali M, Thomson M. Consumption of a garlic clove a day could be beneficial in preventing thrombosis. Prostaglan Leukot Essent Fatty Acids. 1995;53:211-2.

4. Al-Qattan KK, Khan I, Alnaqeeb MA, Ali M. Thromboxane-B2, prostaglandinE2 and hypertension in the rat 2-kidney 1-clip model: a possible mechanism of the garlic induced hypotension. Prostaglan Leukot Essent Fatty Acids. 2001:64:5-10.

5. Al-Qattan K, Khan I, Alnaqeeb MA, Ali M. Mechanism of garlic (Allium sativum) induced reduction of hypertension in $2 \mathrm{~K}-1 \mathrm{C}$ rats: a possible mediation of $\mathrm{Na} / \mathrm{H}$ exchanger isoform-1. Prostaglan Leuko Essent Fatty Acids. 2003;69:217-39.

6. Al-Qattan K, Thomson M, Al-Mutawa'a S, Al-Hajeri D, Drobiova H, Ali M. Nitric oxide mediates the blood-pressure lowering effect of garlic in the rat two-kidney, one-clip model of hypertension. J Nutr. 2006;136:774S-6.

7. Rees LP, Minney SF, Plummer NT, Slater JH, Skyrme DA. A quantitative assessment of the antimicrobial activity of garlic (Allium sativum). World J Microbiol Biotechnol. 1993;9:303-7.

8. Bordia T, Mohammed N, Thomson M, Ali M. An evaluation of garlic and onion as antithrombotic agents. Prostaglan Leukot Essent Fatty Acids. 1996; 54:183-6.

9. Yoshida H, Iwata N, Katsuzaki H, Naganawa R, Ishikawa K, Fukuda H, et al. Antimicrobial activity of a compound isolated from an oil-macerated garlic extract. Biosci Biotechnol Biochem. 1998;62:1014-7.

10. Anwar M, Meki A. Oxidative stress in Streptozotocin-induced diabetic rats: effects of garlic oil and melatonin. Comp Biochem Physiol A. 2003;135:539-47.

11. Bakri IM, Douglas CW. Inhibitory effect of garlic extract on oral bacteria. Arch Oral Biol. 2005;50:645-51.

12. Ariga T, Seki T. Antithrombotic and anticancer effects of garlic-derived sulfur compounds: a review. Biofactors. 2006;26:93-103.

13. Thomson M, Al-Amin ZM, Al-Qattan KK, Shaban LH, Ali M. Anti-diabetic and hypolipidaemic properties of garlic (Allium sativum) in streptozotocininduced diabetic rats. Int J Diabetes Metabolism. 2006;15:108-15.

14. Capasso A. Antioxidant action and therapeutic efficacy of Allium sativum $L$. Molecules. 2013;18:690-700.

15. Amagase $H$, Petesch BL, Matsuura $H$, Kasuga S, Itakura $Y$. Intake of garlic and its bioactive components. J Nutr. 2001;131:955S-62.

16. Wakunaga Company: http://www.kyolic.com/the-kyolic-difference/. Accessed 19 Jan 2016.

17. Rahman K, Lowe GM. Garlic and cardiovascular disease. J Nutr. 2006;136:736S-40.

18. Borek C. Antioxidant health effects of aged garlic extract. J Nutr. 2001; 131:1010S-5.

19. Allison GL, Lowe GM, Rahman K. Aged garlic extract and its constituents inhibit platelet aggregation through multiple mechanisms. J Nutr. 2006; 136:782S-8.

20. Allison GL, Lowe GM, Rahman K. Aged garlic extract inhibits platelet activation by increasing intracellular CAMP and reducing the interaction of GPIIb/Illa with fibrinogen. Life Sci. 2012;91:1275-80. 
21. Morihara N, Hayama M, Fujii H. Aged garlic extract scavenges superoxide radicals. Plant Food Hum Nutr. 2011;66:17-21.

22. Maldonado PD, Barrera D, Medina-Campos ON, Hernandez-Pando R, IbarraRubio ME, Pedraza-Chaverri J. Aged garlic attenuates gentamicin-induced renal damage and oxidative stress in rats. Life Sci. 2003;73:2543-56.

23. Colin-Gonzalez AL, Santana RA, Silva-Islas CA, Chanez-Cardenas ME, Santamaria A, Maldonado PD. The antioxidant mechanisms underlying the aged garlic extract- and S-allylcysteine-induced protection. Oxid Med Cell Longev. 2012. doi:10.1155/2012/907162.

24. Dillon SA, Burmi RS, Lowe GM, Billington D, Rahman K. Antioxidant properties of aged garlic extract: an in vitro study incorporating human low density lipoprotein. Life Sci. 2003;72:1583-94

25. Jakus $V$. The role of free radicals, oxidative stress and antioxidants systems in diabetic vascular disease. Bratisl Lek Listy. 2000;101:541-51.

26. Maritim A, Sanders R, Watkins J. Diabetes, oxidative stress, and antioxidants: a review. J Biochem Mol Toxicol. 2003;17:24-38.

27. Ahmed R. The physiological and biochemical effects of diabetes on the balance between oxidative stress and antioxidant defense system. Med J Islam World Acad Sci. 2005;15:31-42.

28. Goycheva P, Gadjeva V, Popov B. Oxidative stress and its complications in diabetes mellitus. Trakia J Sci. 2006;4:1-8.

29. Maxwell SRJ, Thomason H, Sandler D, Leguen C, Baxter MA, et al. Antioxidant status in patients with uncomplicated insulin-dependent and non-insulin-dependent diabetes mellitus. Eur J Clin Invest. 1997;27:484-90.

30. Giacco F, Brownlee M. Oxidative stress and diabetic complications. Circ Res. 2010;10:1058-70.

31. Drobiova H, Thomson M, Al-Qattan K, Peltonen-Shalaby R, Al-Amin Z, Ali M. Garlic increases antioxidant levels in diabetic and hypertensive rats determined by a modified peroxidase method. Evid Based Complement Alternat Med. 2011. doi:10.1093/ecam/nep011.

32. Eidi A, Eidi M, Esmaeli E. Antidiabetic effect of garlic (Allium sativum L.) in normal and streptozotocin-induced diabetic rats. Phytomed. 2006;13:624-9.

33. Sheela CG, Augusti KT. Antidiabetic effects of S-allylcysteinesulphoxide isolated from garlic Allium sativum Linn. Ind J Exp Biol. 1992;30:523-6.

34. Sheela CG, Kumud K, Augusti KT. Anti-diabetic effects of onion and garlic sulfoxide amino acids in rats. Planta Med. 1995:61:356-7.

35. Liu CT, Hse H, Lii CK, Chen PS, Sheen LY. Effects of garlic oil and diallyltrisulfide on glycemic control in diabetic rats. Eur J Pharmacol. 2005;516:165-73.

36. Shiju TM, Rajesh NG, Viswanathan P. Renoprotective effect of aged garlic extract in streptozotocin-induced diabetic rats. Ind J Pharmacol. 2013;45:18-23.

37. Balamash K, Albar O, Wang Q, Ahmed N. Effect of Kyolic ${ }^{\circledast}$ aged garlic extract on glycaemia, lipidaemia and oxidative stress in patients with type 2 diabetes mellitus. J Diab Res Clin Metab. 2012. http://www.hoajonline/ jdrcm/2050-0866/1/18 - 0866-1 - 18.

38. National Research Council (NRC). Guide for the Care and Use of Animals. Institute for Laboratory Animal Research, Commission on Life Sciences, Washington, The National Academies Press, 1996

39. Aebi H. Catalase. In: Bergmeyer HU, editor. Methods in enzyme analysis, vol. 2. New York: Academic; 1974. p. 673-84.

40. Ohkawa $H$, Ohishi N, Yake Y. Assay for lipid peroxides in animal tissues by thiobarbituric acid reaction. Anal Biochem. 1973:95:351-8.

41. Bradford M. A rapid and sensitive method for the quantitation of microgram quantities of protein utilizing the principle of protein-dye binding. Anal Biochem. 1976;72:248-54.

42. American Diabetes Association (ADA). Diagnosis and classification of diabetes mellitus. Diabetes Care. 2010;33:S62-9.

43. Kiran G, Nandini CD, Ramesh HP, Salimath PV. Progression of early phase diabetic nephropathy in streptozotocin-induced diabetic rats: evaluation of various kidney-related parameters. Ind J Exp Biol. 2012;50:133-40.

44. Thomson M, Al-Qattan KK, Divya JS, Ali M. Ameliorative actions of garlic (Allium sativum) and ginger (Zingiber officinale) on biomarkers of diabetes and diabetic nephropathy in rats: comparison to aspirin. Int J Pharmacol. 2013;9:501-12.

45. Adewole SO, Ojewole JAO. Effects of insulin on pancreatic $\beta$-cells of streptozotocin-treated diabetic rats: Experimental observations on immunohistological and morphological changes. Pharmacol Online. 2006;1:120-34

46. Akbarzadeh A, Norouzian C, Mehrabi MR, Samshidi S, Farhahgi A, Allah Verdi A, et al. Induction of diabetes by streptozotocin in rats. Ind J Clin Biochem. 2007;22:60-4.

47. Ahmed N. Advanced glycation endproducts - role in pathology of diabetic complications. Diabetes Res Clin Prac. 2006;67:3-21.
48. Ahmad MS, Pischetsrieder M, Ahmed N. Aged garlic extract and S-allylcysteine prevent formation of advanced glycation endproducts. Eur J Pharmacol. 2007:561:32-8.

49. Dixit AK, Dey R, Suresh A, Chaudhuri S, Panda AK, Mitra A, et al. The prevalence of dyslipidemia in patients with diabetes mellitus of ayurveda Hospital. J Diab Metab Disorders. 2014;13. http://idmdonline.biomedcentral. com/articles.10.1186/2251-6581-13-58.

50. Moorandian AD. Dyslipidemia in type 2 diabetes mellitus. Nature Rev Endocrinol. 2009:5:150-9.

51. Yeh YY, Liu L. Cholesterol-lowering effect of garlic extracts and organosulfur compounds: human and animal studies. J Nutr. 2001;131:989S-93.

52. Saravanan G, Ponmurugan P, Kumar GPS, Rajarajan T. Antidiabetic properties of S-allyl cysteine, a garlic component on streptozotocin-induced diabetes in rats. J Appl Biomed. 2009;7:151-9.

\section{Submit your next manuscript to BioMed Central and we will help you at every step:}

- We accept pre-submission inquiries

- Our selector tool helps you to find the most relevant journal

- We provide round the clock customer support

- Convenient online submission

- Thorough peer review

- Inclusion in PubMed and all major indexing services

- Maximum visibility for your research

Submit your manuscript at www.biomedcentral.com/submit
Biomed Central 